Article

\title{
Magnetically recoverable, nanoscale-supported heteropoly acid catalyst for green synthesis of biologically active compounds in water
}

\author{
Ezzat Rafiee*, Sara Eavani, Maryam Khodayari \\ Faculty of Chemistry, Razi University, Kermanshah, 67149, Iran
}

\section{A R T I C L E I N F O}

Article history:

Received 20 December 2012

Accepted 25 March 2013

Published 20 August 2013

\section{Keywords:}

Core-shell particle

Magnetically recoverable catalyst

Heteropoly acid

Xanthene

Hydroacridine

\begin{abstract}
A B S T R A C T
12-Tungstophosphoric acid supported on aerosil silica and silica-coated $\gamma-\mathrm{Fe}_{2} \mathrm{O}_{3}$ nanoparticles was prepared and characterized using transmission electron microscopy, scanning electron microscopy, and inductively coupled plasma atomic emission spectroscopy. The catalytic activity of the two prepared catalysts was compared in the synthesis of 1,8-dioxo-9,10-diaryldecahydroacridines in water. 12-Tungstophosphoric acid was highly dispersed on the silica-coated $\gamma$ - $\mathrm{Fe}_{2} \mathrm{O}_{3}$ nanoparticles and showed higher activity and a higher reuse number compared with the acid supported on aerosil silica. The catalyst could be recovered simply by using an external magnetic field and could be reused several times without appreciable loss of its catalytic activity.
\end{abstract}

(C) 2013, Dalian Institute of Chemical Physics, Chinese Academy of Sciences. Published by Elsevier B.V. All rights reserved.

\section{Introduction}

The heterogenization of homogeneous catalytic materials is an attractive strategy for overcoming the difficulties involved in the separation and reusability of homogeneous catalysts. Heteropoly acids (HPAs) are suitable choices as catalysts because of their strong Brönsted acidities, high thermal stabilities, and structural flexibilities, and also because their low volatilities and low corrosive properties make them suitable for green technology applications [1-3]. Heterogenization or immobilization of such catalysts is usually required for ease of recycling and ease of separation of the catalysts from the reaction products [4-6]. The nature of the support affects the acidity, activity, and leaching of the catalyst. An increased interest in the heterogenization of supported HPAs has arisen because of the superior activities of these systems compared with those of bulk HPAs [7-9]. Supported systems are also of practical im- portance because the catalytic activity is determined by the catalyst surface area for some HPA-catalyzed reactions [10-13].

In this study, two different kinds of materials, namely aerosil silica and silica-coated $\gamma-\mathrm{Fe}_{2} \mathrm{O}_{3}$ nanoparticles, were used as supports for the immobilization of HPAs. The effects of these supports on the catalyst acidity, activity, leaching, and recyclability were investigated. Based on the obtained results, a specific heterogeneous HPA catalyst was used for the syntheses of biologically useful building blocks, namely 1,8-dioxo-9,10-diaryldecahydroacridines, 1,8-dioxooctahydroxanthenes, and 14-aryl-14H-dibenzo[a,j]xanthenes (Scheme 1) [14-16]. Although many methods are available for the syntheses of these compounds [17-24], there is still a scope for further research on the development of one-pot, facile, and efficient processes using green heterogeneous solid acid catalysts in water. It is expected that these catalysts will provide a model for preparing

\footnotetext{
*Corresponding author. Tel/Fax: +98-831-4274559; E-mail: e.rafiei@razi.ac.ir, ezzat_rafiee@yahoo.com This work was supported by Razi University Research Council and Iran National Science Foundation. 
<smiles>[R][R]1ccccc1C1C2=C(CC(C)(C)CC2=O)N([R])C2=C1C(=O)CC(C)(C)C2</smiles>

1,8-dioxo-9,10-diaryl-decahydroacridines<smiles>[R]c1cccc(C2C3=C(CC(C)(C)CC3=O)OC3=C2C(=O)CC(C)(C)C3)c1</smiles>

1,8-dioxo-octahydroxanthenes<smiles>[Al]C1c2c(ccc3ccccc23)Oc2ccc3ccccc3c21</smiles>

14-aryl-14H-dibenzo[a,j]xanthenes

Scheme 1. Structures of biologically active compounds synthesized in this study.

supported HPA catalysts for use in the syntheses of other biologically active compounds in water.

\section{Experimental}

\subsection{Catalyst preparation}

The reagents and solvents used in this work were obtained from Fluka, Aldrich, or Merck and were used without further purification. The catalyst samples were prepared by immobilization of $40 \mathrm{wt} \%$ of $\mathrm{H}_{3} \mathrm{PW}_{12} \mathrm{O}_{40}$ (PW) on the surfaces of aerosil silica $\left(S_{\mathrm{BET}}=311 \mathrm{~m}^{2} / \mathrm{g}\right)$ [9] and silica-coated $\gamma-\mathrm{Fe}_{2} \mathrm{O}_{3}$ nanoparticles $\left(\mathrm{Fe}_{2} \mathrm{O}_{3} @ \mathrm{SiO}_{2} \mathrm{NPs}\right)$ [25]. These samples were designated $\mathrm{PW} / \mathrm{SiO}_{2}$ and $\mathrm{Fe}_{2} \mathrm{O}_{3} @ \mathrm{SiO}_{2}-\mathrm{PW}$, respectively. The $\mathrm{W}$ content determined using ICP-AES was slightly lower than that expected from the preparation stoichiometry. Typically, PW loadings of ca. $29.2 \mathrm{wt} \%$ for the $\mathrm{PW} / \mathrm{SiO}_{2}$ sample and ca. 33.4 $\mathrm{wt} \%$ for the $\mathrm{Fe}_{2} \mathrm{O}_{3} @ \mathrm{SiO}_{2}$-PW sample were obtained.

\subsection{Catalyst characterization}

Transmission electron microscopy (TEM) was performed using a TEM microscope (Philips CM $120 \mathrm{kV}$, the Netherlands). The morphologies of the supported catalysts were observed by scanning electron microscopy (SEM) using a model XL30 Philips SEM. The W contents were determined by inductively coupled plasma atomic emission spectroscopy (ICP-AES) using a Spectro Ciros CCD spectrometer. The potential variations were measured with a Hanna $302 \mathrm{pH}$ meter and a double-junction electrode.

\subsection{Synthesis of three biologically active compounds}

For synthesis of 1,8-dioxo-9,10-diaryldecahydroacridines, a mixture of an aldehyde (1.0 mmol), 5,5-dimethyl-1,3-cyclohexanedione (dimedone, $2.0 \mathrm{mmol})$, an amine $(1.0 \mathrm{mmol})$, and $\mathrm{Fe}_{2} \mathrm{O}_{3} @ \mathrm{SiO}_{2}$-PW catalyst (0.02 g) in water (5 ml) was stirred under reflux conditions. After completion of the reaction, indicated by thin-layer chromatography (TLC), the mixture was cooled to room temperature and the solid (containing catalyst and product) was filtered off and washed with water $(10 \mathrm{ml})$. The product was dissolved in acetonitrile, and the catalyst was separated from the product using an external magnet. The solvent was evaporated in a vacuum to give the crude product, which was purified by recrystallization from ethanol.

For synthesis of 1,8-dioxooctahydroxanthenes, a mixture of an aldehyde $(1.0 \mathrm{mmol})$, dimedone $(2.0 \mathrm{mmol})$, and $\mathrm{Fe}_{2} \mathrm{O}_{3} @ \mathrm{SiO}_{2}-\mathrm{PW}$ catalyst $(0.02 \mathrm{~g})$ in water ( $\left.5 \mathrm{ml}\right)$ was refluxed, and the reaction was monitored by TLC. After completion of the reaction, the catalyst was separated and the product was purified according to the above procedure.

For synthesis of 14-aryl-14H-dibenzo[a,j]xanthenes, a mix-
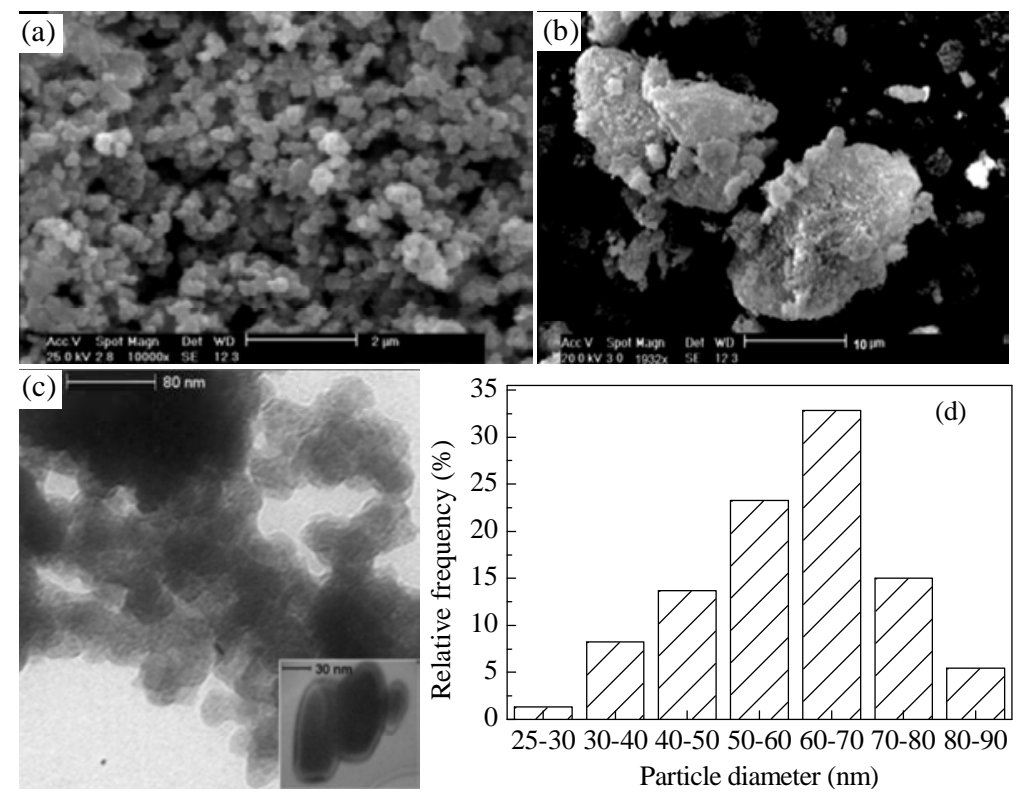

Fig. 1. SEM images of $\mathrm{Fe}_{2} \mathrm{O}_{3} @ \mathrm{SiO}_{2}-\mathrm{PW}(\mathrm{a})$ and $\mathrm{PW} / \mathrm{SiO}_{2}$ (b) catalysts, and TEM image (c) and diameter histogram (d) of $\mathrm{Fe}_{2} \mathrm{O}_{3} @ \mathrm{SiO}_{2}-\mathrm{PW}$ catalyst. 
ture of 2-naphthol (2.0 mmol), an aldehyde (1.0 mmol), and $\mathrm{Fe}_{2} \mathrm{O}_{3} @ \mathrm{SiO}_{2}$-PW catalyst ( $\left.0.02 \mathrm{~g}\right)$ in water $(5 \mathrm{ml})$ was stirred under reflux conditions for an appropriate time. Purification of the products and recycling of the catalyst were similar to the procedures described above.

\section{Results and discussion}

The morphological features of the catalysts were observed using SEM. The $\mathrm{Fe}_{2} \mathrm{O}_{3} @ \mathrm{SiO}_{2}$-PW catalyst had a uniform and spherical morphology (Fig. 1(a)), but the $\mathrm{PW} / \mathrm{SiO}_{2}$ catalyst consisted of a PW layer composed of several aggregates of PW particles rather than a continuous film (Fig. 1(b)). TEM observations indicated that $\mathrm{Fe}_{2} \mathrm{O}_{3} @ \mathrm{SiO}_{2}-\mathrm{PW}$ had a well-defined core-shell structure, almost spherical in shape, and of diameter 60-70 nm (Fig. 1(c) and (d)). The surface area of the nanoscale $\mathrm{Fe}_{2} \mathrm{O}_{3} @ \mathrm{SiO}_{2}$ support was higher than that of commercial $\mathrm{SiO}_{2}$, leading to higher dispersion of PW and a higher PW loading capacity.

The catalytic activities of the samples were compared using the reaction of benzaldehyde, dimedone, and 4-ethylaniline in water. The reaction was carried out at $70{ }^{\circ} \mathrm{C}$ because of the low solubility of dimedone in the reaction mixture at lower temperatures. The results are summarized in Table 1. A blank experiment in the absence of a catalyst showed that a catalyst is essential in this reaction (Table 1, entry 1 ). The effects of aerosil silica and $\mathrm{Fe}_{2} \mathrm{O}_{3} @ \mathrm{SiO}_{2}$ NPs on the product yield were poor (Table 1, entries 2 and 3). The catalytic activities of $\mathrm{SiO}_{2}$ and $\mathrm{Fe}_{2} \mathrm{O}_{3} @ \mathrm{SiO}_{2}$ are attributed to the presence of $\mathrm{Si}-\mathrm{OH}$ groups on the outer surfaces of these supports. $\mathrm{Fe}_{2} \mathrm{O}_{3} @ \mathrm{SiO}_{2}$ NPs have large surface-to-volume ratios and therefore have highly dispersed surface functional groups compared with $\mathrm{SiO}_{2}$, and this may lead to improved catalytic activity. $\mathrm{PW} / \mathrm{SiO}_{2}$ gave a moderate yield (Table 1, entry 4). When $\mathrm{Fe}_{2} \mathrm{O}_{3} @ \mathrm{SiO}_{2}-\mathrm{PW}$ was used as the catalyst, a significant improvement in the yield was observed (Table 1, entry 5). Although the $\mathrm{Fe}_{2} \mathrm{O}_{3} @ \mathrm{SiO}_{2}-\mathrm{PW}$ and $\mathrm{PW} / \mathrm{SiO}_{2}$ catalysts had similar PW loadings (according to ICP-AES analysis), they had different monolayer coverage ca-

Table 1

Catalytic activity of various solid acids in model reaction.

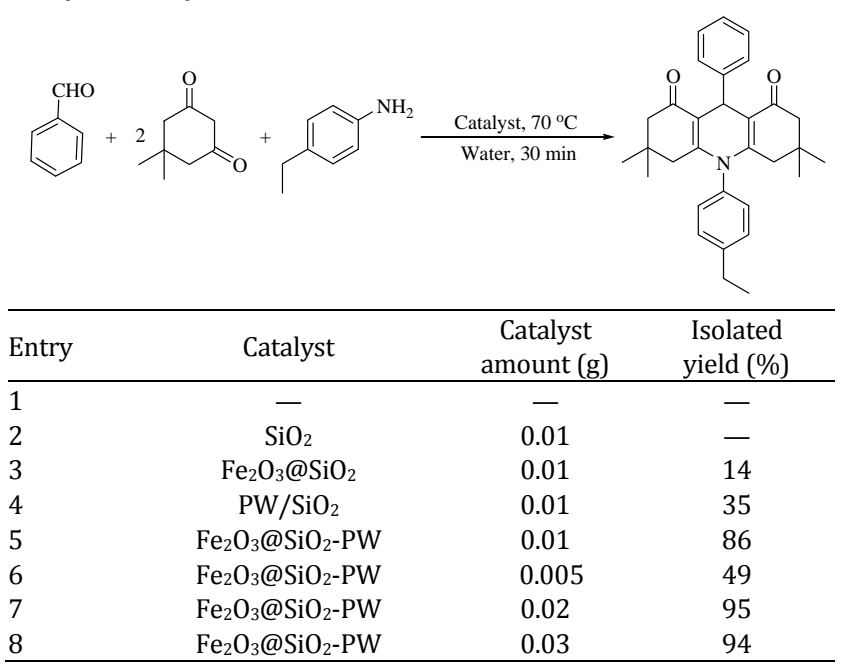

pacities. In the case of $\mathrm{PW} / \mathrm{SiO}_{2}$, the predominant formation of multilayers resulted in lower dispersion of intact PW anions on the silica support, leading to low accessibility of protons for participation in the reaction. However, in $\mathrm{Fe}_{2} \mathrm{O}_{3} @ \mathrm{SiO}_{2}-\mathrm{PW}, \mathrm{PW}$ formed a monolayer of isolated Keggin anions on the exterior surface of the support, so a large number of active sites were exposed to the surface, and therefore this catalyst exhibited excellent activity in the reaction.

In order to compare the reusabilities of the $\mathrm{Fe}_{2} \mathrm{O}_{3} @ \mathrm{SiO}_{2}-\mathrm{PW}$ and $\mathrm{PW} / \mathrm{SiO}_{2}$ catalysts, model reactions were carried out using $0.10 \mathrm{~g}$ of each catalyst, and the experiments were appropriately scaled up. At the end of the reaction, the mixture was centrifuged and water was removed from the mixture to leave a residue (containing the product and catalyst). The product was dissolved in acetonitrile and the catalyst was separated from the product by filtration (for $\mathrm{PW} / \mathrm{SiO}_{2}$ ) or by attaching an external magnet to the reaction vessel, followed by decantation of the product solution (for $\mathrm{Fe}_{2} \mathrm{O}_{3} @ \mathrm{SiO}_{2}-\mathrm{PW}$ ). The catalyst was then dried and used in the next run. The $\mathrm{PW} / \mathrm{SiO}_{2}$ catalyst had poor reusability, and significant loss of catalytic activity was observed after the first run (Fig. 2(a)). This was caused by leaching of PW from the support into the reaction mixture, and was measured using ICP-AES (Fig. 2(b)). The acid strengths and quantities of acid sites of the catalysts were examined by po-

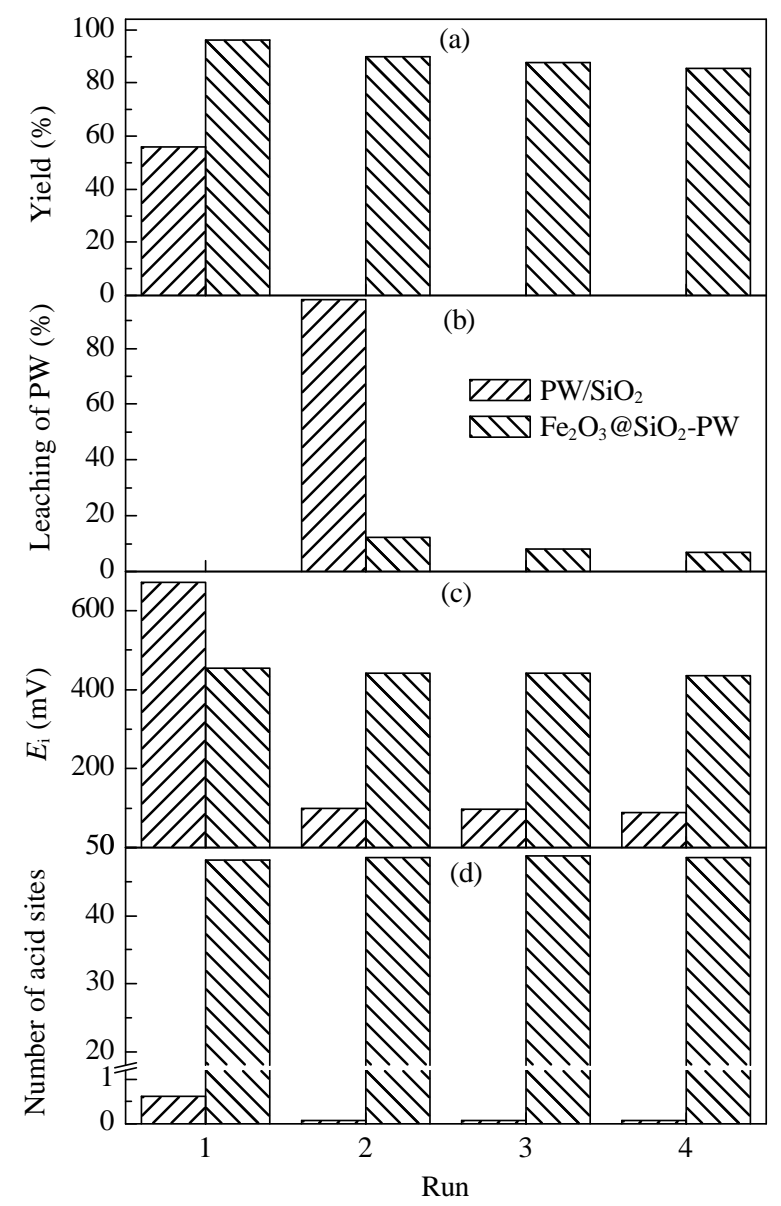

Fig. 2. Catalyst reusability. (a) Catalyst activity; (b) Leaching of PW measured by ICP-AES; (c) Catalyst acid strength indicated by initial electrode potential $\left(E_{\mathrm{i}}\right)$; (d) Quantities of acid sites of the catalysts. 
tentiometric titration with $n$-butylamine $[10,11]$. This method enables the determination of the total number of acid sites and their distribution. As a criterion for interpreting the obtained results, the initial electrode potential $\left(E_{\mathrm{i}}\right)$ was taken to indicate the maximum acid strength of the sites. The number of millimoles of amine per gram of solid needed to reach the plateau indicated the total number of acid sites. The $\mathrm{PW} / \mathrm{SiO}_{2}$ sample had strong acid sites, which might indicate a low interaction level and the predominant formation of less dispersed intact PW anions on the silica support. This supported catalyst therefore showed significant leaching of PW in water, and its acid strength and the total number of acid sites decreased significantly after the first run (Fig. 2(c) and (d)). The potentiometric results for the $\mathrm{Fe}_{2} \mathrm{O}_{3} @ \mathrm{SiO}_{2}$-PW sample showed a lower $E_{\mathrm{i}}$ value compared with that of the $\mathrm{PW} / \mathrm{SiO}_{2}$ sample for the first run, which may be a consequence of strong interactions with the support in $\mathrm{Fe}_{2} \mathrm{O}_{3} @ \mathrm{SiO}_{2}$-PW. The interacting species were well dispersed on the support surface and did not leach during the reaction. So, the $\mathrm{Fe}_{2} \mathrm{O}_{3} @ \mathrm{SiO}_{2}-\mathrm{PW}$ catalyst could be recovered and reused several times (Fig. 2); only $27.3 \%$ of the initial PW content totally leached into the reaction mixture during four successive runs. The yield of the product was not substantially changed (10\% difference) after the fourth run. The potentiometric titration results showed that most of the acid sites were preserved during four cycles (Fig. 2(d)).

The above results show that the use of nanoscale $\mathrm{Fe}_{2} \mathrm{O}_{3} @ \mathrm{SiO}_{2}$ as a support leads to excellent PW distribution and a higher number of surface active sites, compared with an aerosil silica support. Complete recovery of the $\mathrm{Fe}_{2} \mathrm{O}_{3} @ \mathrm{SiO}_{2}-\mathrm{PW}$ catalyst using an external magnetic field and improved recy-

\section{Table 2}

$\mathrm{Fe}_{2} \mathrm{O}_{3} @ \mathrm{SiO}_{2}-\mathrm{PW}$-catalyzed synthesis of 1,8-dioxo-9,10-diaryl-decahydroacridine derivatives.

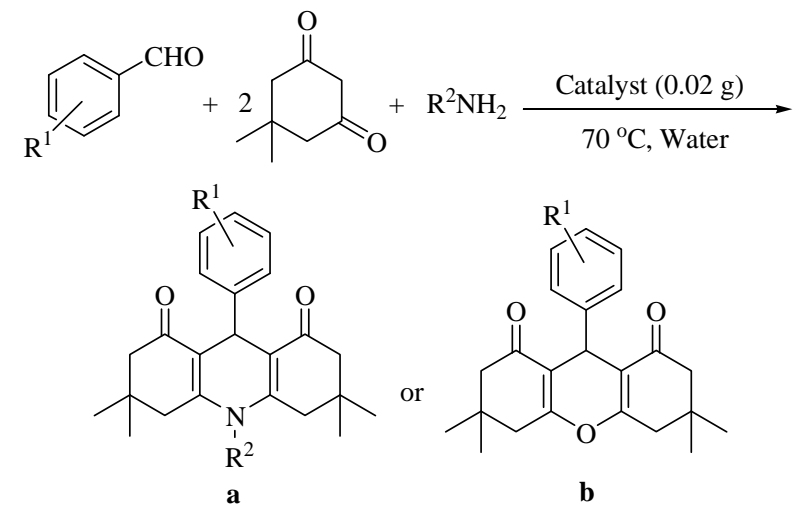

\begin{tabular}{lccccc}
\hline Entry & $\mathrm{R}^{1}$ & $\mathrm{R}^{2}$ & Product $^{\mathrm{a}}$ & $\begin{array}{c}\text { Time } \\
(\mathrm{min})\end{array}$ & $\begin{array}{c}\text { Isolated } \\
\text { yield (\%) }\end{array}$ \\
\hline 1 & $\mathrm{H}$ & $\mathrm{C}_{6} \mathrm{H}_{5}$ & $\mathbf{1 a}$ & 30 & 74 \\
2 & $\mathrm{H}$ & $\mathrm{C}_{6} \mathrm{H}_{5} \mathrm{CH}_{2}$ & $\mathbf{2 a}$ & 45 & 81 \\
3 & $\mathrm{H}$ & $4-\mathrm{CH}_{3} \mathrm{CH}_{2}-\mathrm{C}_{6} \mathrm{H}_{5}$ & $\mathbf{3 a}$ & 30 & 95 \\
4 & $4-\mathrm{CH}_{3}$ & $4-\mathrm{CH}_{3} \mathrm{CH}_{2}-\mathrm{C}_{6} \mathrm{H}_{5}$ & $\mathbf{4 a}$ & 30 & 93 \\
5 b & $4-\mathrm{Cl}^{\mathrm{a}}$ & $4-\mathrm{CH}_{3} \mathrm{CH}_{2}-\mathrm{C}_{6} \mathrm{H}_{5}$ & $\mathbf{5 a}$ & 30 & 94 \\
$6{ }^{\mathrm{b}}$ & $3-\mathrm{NO}_{2}$ & $4-\mathrm{CH}_{3} \mathrm{CH}_{2}-\mathrm{C}_{6} \mathrm{H}_{5}$ & $\mathbf{6 a}$ & 25 & 96 \\
7 & $\mathrm{H}$ & $4-\mathrm{Cl}_{6} \mathrm{C}_{5}$ & $\mathbf{7 b}$ & 40 & 61 \\
8 & $\mathrm{H}$ & $4-\mathrm{NO}_{2}-\mathrm{C}_{6} \mathrm{H}_{5}$ & $\mathbf{8 b}$ & 40 & 90 \\
\hline
\end{tabular}

a All products were identified by comparing their spectral data with those of the authentic samples $[23,26]$.

b $0.05 \mathrm{~g}$ of SDS was used in these reactions. cling and reuse compared with $\mathrm{PW} / \mathrm{SiO}_{2}$ are other advantages that favor the use of $\mathrm{Fe}_{2} \mathrm{O}_{3} @ \mathrm{SiO}_{2}$ NPs for immobilization of HPAs.

To investigate the effect of the catalyst loading, the model reaction was carried out in the presence of different amounts of $\mathrm{Fe}_{2} \mathrm{O}_{3} @ \mathrm{SiO}_{2}-\mathrm{PW}$ catalyst. The best result was obtained in the presence of $0.02 \mathrm{~g}$ of $\mathrm{Fe}_{2} \mathrm{O}_{3} @ \mathrm{SiO}_{2}-\mathrm{PW}$; the use of higher amounts of catalyst had no effect on the product yield (Table 1 , entries 5-8).

The catalytic system was used to synthesize structurally diverse 1,8-dioxo-9,10-diaryldecahydroacridine derivatives; the results are summarized in Table 2 . Benzylamine, aniline, and aromatic amines with electron-donating group gave the expected product a (Table 2, entries 1-6), whereas amines substituted with electron-withdrawing groups gave 1,8-dioxooctahydroxanthene derivatives (Table 2, entries 7 and 8). Benzaldehyde and other aromatic aldehydes were used and were found to react well to give the corresponding 1,8-dioxo-9,10diaryldecahydroacridines in excellent yields (Table 2, entries 1-6). However, because solid aldehydes are insoluble in aqueous media, it was necessary to use a surfactant to solubilize these compounds in water (Table 2, entries 5 and 6).

Encouraged by these results, we used the $\mathrm{Fe}_{2} \mathrm{O}_{3} @ \mathrm{SiO}_{2}-\mathrm{PW}$ catalyst in the reaction of dimedone or 2-naphthol with various aromatic aldehydes, affording a series of xanthene derivatives in excellent yields, in short reaction times (Table 3)

The proposed mechanism for the synthesis of 1,8-dioxo9,10-diaryldecahydroacridines a is shown in Scheme 2. First, the acid catalyst converts the aldehyde into a convenient electrophile via protonation of the carbonyl group, and then one molecule of dimedone condenses with the aromatic aldehyde to produce intermediate $\mathbf{I}$. Then, a second activated dimedone

\section{Table 3}

$\mathrm{Fe}_{2} \mathrm{O}_{3} @ \mathrm{SiO}_{2}$-PW-catalyzed synthesis of xanthene derivatives.

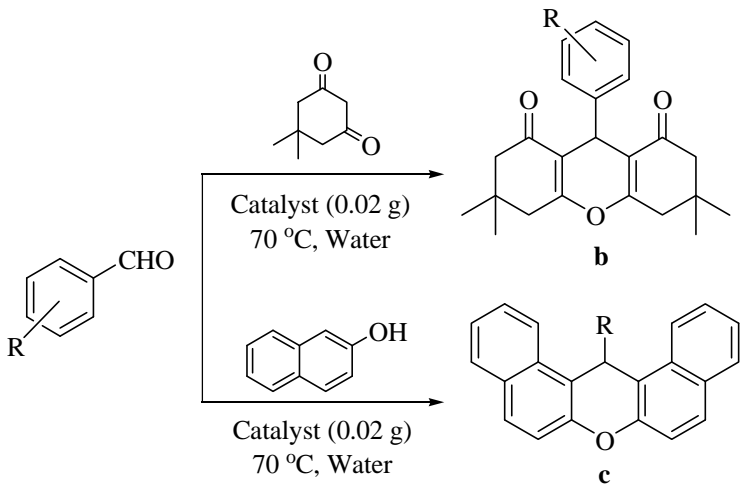

\begin{tabular}{lcccc}
\hline Entry & $\mathrm{R}$ & Product $^{\mathrm{a}}$ & $\begin{array}{c}\text { Time } \\
(\mathrm{min})\end{array}$ & $\begin{array}{c}\text { Isolated } \\
\text { yield (\%) }\end{array}$ \\
\hline 1 & $\mathrm{H}$ & $\mathbf{1 b}$ & 25 & 94 \\
2 & $4-\mathrm{CH}_{3}$ & $\mathbf{2 b}$ & 30 & 95 \\
3 & $4-\mathrm{OCH}_{3}$ & $\mathbf{3 b}$ & 55 & 84 \\
4 & $2-\mathrm{Cl}$ & $\mathbf{4 b}$ & 60 & 96 \\
5 & $\mathrm{H}$ & $\mathbf{5 c}$ & 30 & 93 \\
6 & $4-\mathrm{CH}_{3}$ & $\mathbf{6 c}$ & 30 & 94 \\
7 & $4-\mathrm{OCH}_{3}$ & $\mathbf{7 c}$ & 45 & 72 \\
8 & $2-\mathrm{Cl}$ & $\mathbf{8 c}$ & 30 & 90 \\
\hline
\end{tabular}




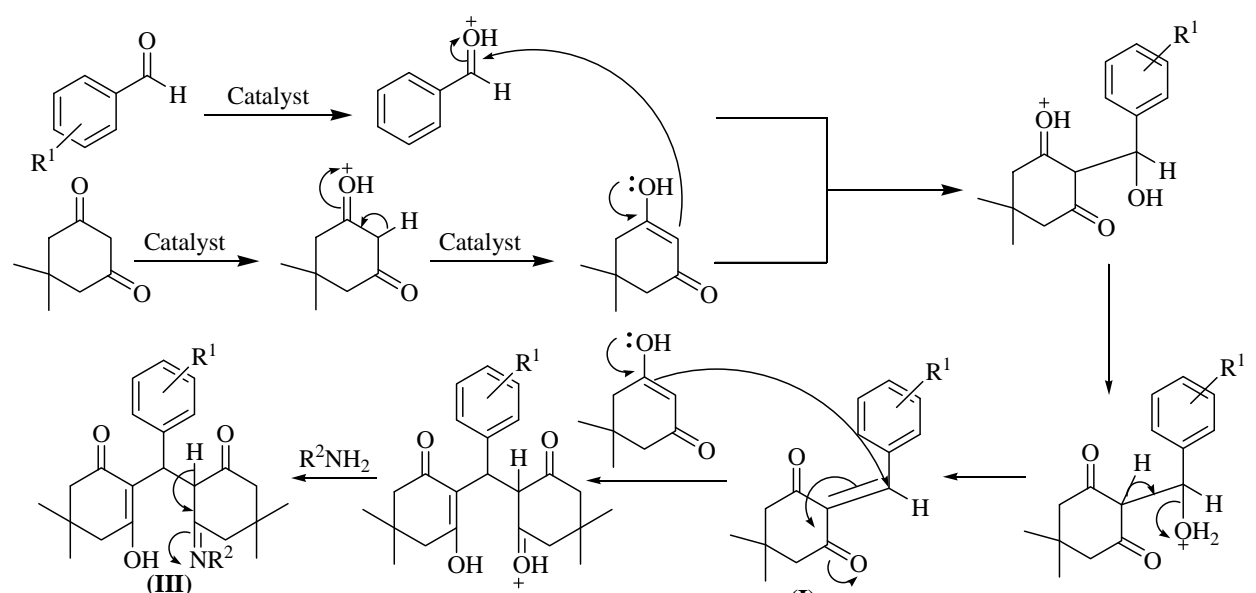
(III)

(II)

(I)

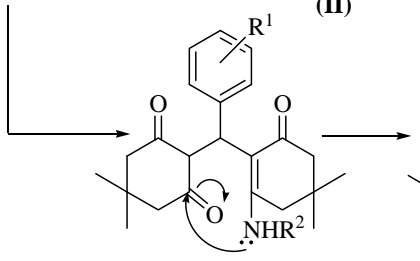<smiles>[R]c1ccc(C2CC(=O)CC(C)(C)CC(O)(CCC)N([R])C3=C2C(=O)CC(C)(C)C3)cc1</smiles><smiles>[R]N1C2=C(C(=O)CC(C)(C)C2)C(c2ccccc2)C2=C1CC(C)(C)CC2=O</smiles>

Scheme 2. The proposed mechanism for the synthesis of 1,8-dioxo-9,10-diaryl-decahydroacridines.

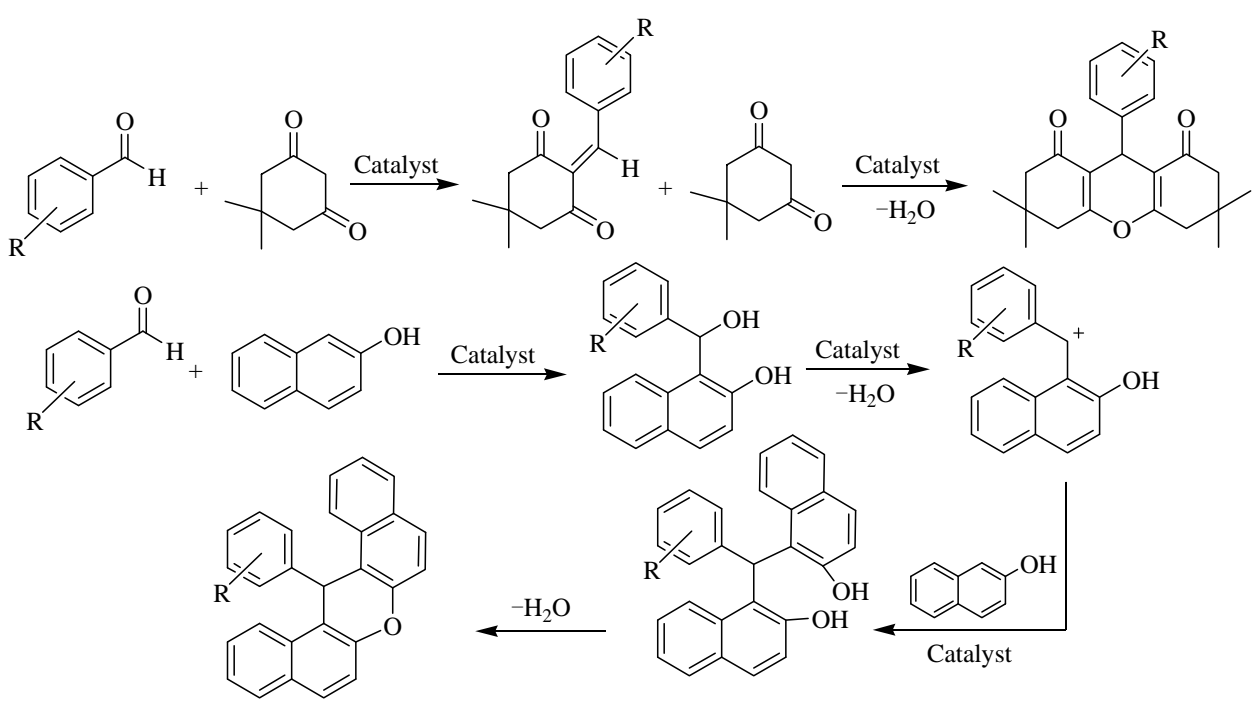

Scheme 3. The proposed mechanism for the synthesis of xanthene derivatives.

reacts with I to give intermediate II. Nucleophilic attack of an amine group on a carbonyl group creates intermediate III. In the next step, cyclization occurs by nucleophilic attack of an amine group on a carbonyl group. Finally, by the removal of one water molecule, the acridine derivatives are generated. Similar to the mechanism in Scheme 2, the interaction of an aldehyde with the catalyst surface generates an electrophilic carbon center, followed by nucleophilic attack of the activated dimedone or 2-naphthol to generate the xanthene derivatives (Scheme 3).

\section{Conclusions}

Nanoscale supports such as $\mathrm{Fe}_{2} \mathrm{O}_{3} @ \mathrm{SiO}_{2}$ have higher catalyst loading capacities and higher dispersions than many con- ventional support matrices, leading to improved catalytic activities of HPA-supported catalysts. Moreover, the magnetic properties of $\mathrm{Fe}_{2} \mathrm{O}_{3}$ enable complete recovery of the $\mathrm{Fe}_{2} \mathrm{O}_{3} @ \mathrm{SiO}_{2}-\mathrm{PW}$ catalyst using an external magnetic field; this is an important advantage of the use of a magnetically separable catalyst. The $\mathrm{Fe}_{2} \mathrm{O}_{3} @ \mathrm{SiO}_{2}$-PW catalyst was used in a novel methodology for the aqueous syntheses of 1,8-dioxo-9,10-diaryldecahydroacridines, 1,8-dioxooctahydroxanthenes, and 14-aryl-14H-dibenzo[a,j] xanthenes, which are biologically interesting compounds. The use of water as the solvent, low catalyst loading, simple work-up for the isolation of high-purity products in excellent yields, mild reaction conditions, and catalyst recyclability are features of this new procedure. These characteristics of our protocol make the reaction suitable for scale-up and commercialization. 


\section{Graphical Abstract}

Chin. J. Catal., 2013, 34: 1513-1518 doi: 10.1016/S1872-2067(12)60645-7

Magnetically recoverable, nanoscale-supported heteropoly acid catalyst for green synthesis of biologically active compounds in water

Ezzat Rafiee*, Sara Eavani, Maryam Khodayari

Razi University, Iran

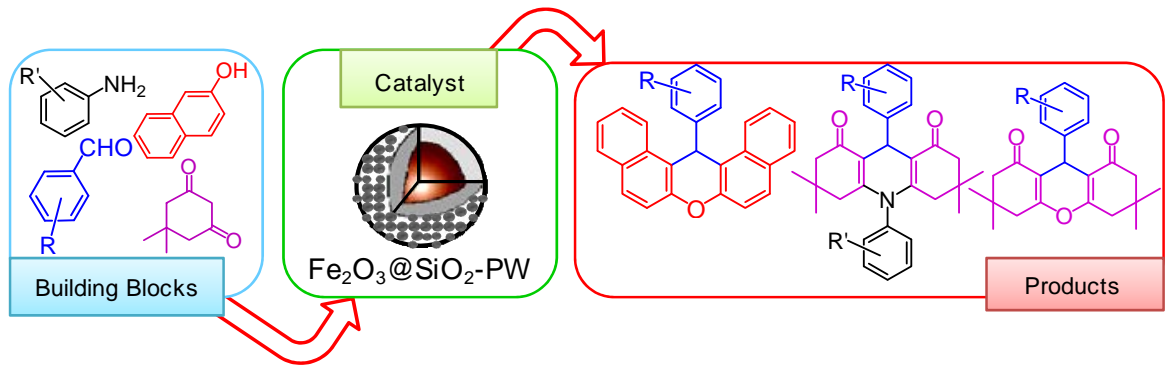

12-Tungstophosphoric acid (PW) catalysts supported on aerosil silica and silica-coated $\gamma$ - $\mathrm{Fe}_{2} \mathrm{O}_{3}$ nanoparticles $\left(\mathrm{Fe}_{2} \mathrm{O}_{3} @ \mathrm{SiO}_{2}-\mathrm{PW}\right)$ were prepared and characterized. These catalysts were used for the aqueous syntheses of 1,8-dioxo-9,10-diaryldecahydroacridines and xanthene derivatives, which are biologically interesting compounds.

\section{Acknowledgments}

We thank the Razi University Research Council and Iran National Science Foundation (INSF) for support of this work.

\section{References}

[1] Misono M. Chem Commun, 2001: 1141

[2] Min J S, Mizuno N. Catal Today, 2001, 71: 89

[3] Kozhevnikov I V. Catal Rev-Sci Eng, 1995, 37: 311

[4] Wu Y, Ye X K, Yang X G, Wang X P, Chu W L, Hu Y C. Ind Eng Chem Res, 1996, 35: 2546

[5] Dias A S, Pillinger M, Valente A A. Microporous Mesoporous Mater, 2006, 94: 214

[6] Zhang Z X, Zhang F W, Zhu Q Q, Zhao W, Ma B C, Ding Y. J Colloid Interface Sci, 2011, 360: 189

[7] Baker L C W, Glick D C. Chem Rev, 1998, 98: 3

[8] Okuhara T. Chem Rev, 2002, 102: 3641

[9] Rafiee E, Joshaghani M, Eavani S, Rashidzadeh S. Green Chem, 2008, 10: 982

[10] Rafiee E, Eavani S, Rashidzadeh S, Joshaghani M. Inorg Chim Acta, 2009, 362: 3555

[11] Rafiee E, Paknezhad F, Shahebrahimi Sh, Joshaghani M, Eavani S, Rashidzadeh S. J Mol Catal A, 2008, 282: 92
[12] Miyaji A, Ohnishi R, Okuhara T. Appl Catal A, 2004, 262: 143

[13] Dias J A, Caliman E, Dias S C L, Paulo M, de Souza A T C P. Catal Today, 2003, 85: 39

[14] Hernandez-Gallegos Z, Lehman-F P A, Hong E, Posadas F, Hernandez-Gallegos E. Eur J Med Chem, 1995, 30: 355

[15] Girault S, Grellier P, Berecibar A, Maes L, Mouray E, Lemiere P, Debreu M A, Davioud-Charvet E, Sergheraet C. J Med Chem, 2000, 43: 2646

[16] Ion R M, Planner A, Wiktorowicz K, Frackowiak D. Acta Biochim Pol, 1998, 45: 833

[17] Shakibaei G I, Mirzaei P, Bazgir A. Appl Catal A, 2007, 325: 188

[18] Bhattacharya A K, Rana K C, Mujahid M, Sehar I, Saxena A K. Bioorg Med Chem Lett, 2009, 19: 5590

[19] Naik M A, Sachdev D, Dubey A. Catal Commun, 2010, 11: 1148

[20] Gong K, Fang D, Wang H L, Zhou X L, Liu Z L. Dyes Pigments, 2009, 80: 30

[21] Shen W, Wang L M, Tian H, Tang J, Yu J J. J Fluorine Chem, 2009, 130: 522

[22] Hong M, Cai C.J Fluorine Chem, 2009, 130: 989

[23] Ko S K, Yao C F. Tetrahedron Lett, 2006, 47: 8827

[24] Kidwai M, Bhatnagar D. Tetrahedron Lett, 2010, 51: 2700

[25] Rafiee E, Eavani S. Green Chem, 2011, 13: 2116

[26] Piao Y, Burns A, Kim J, Wiesner U, Hyeon T. Adv Funct Mater, 2008, 18: 3745

[27] Seyyedhamzeh M, Mirzaei P, Bazgir A. Dyes Pigments, 2008, 76: 836 